\title{
Concomitant polymorphs of aryl-ether amine via catemer and dimer carboxylic acid supramolecular interactions and their effect on optical properties
}

Mehboobali Pannipara ( $\triangle$ mpannipara@kku.edu.sa )

King Khalid University https://orcid.org/0000-0003-4845-838X

Abdullah G Al-Sehemi

King Khalid University

\section{Research Article}

Keywords: polymorphic structure, catemer, supramolecular interactions, aryl ether amine

Posted Date: March 31st, 2021

DOl: https://doi.org/10.21203/rs.3.rs-264441/v1

License: (c) (1) This work is licensed under a Creative Commons Attribution 4.0 International License.

Read Full License 


\section{Abstract}

Carboxylic acid supramolecular synthon exhibited dimer or catemer motifs in the crystal lattice depend on the substituent and other functional groups present in the structure. In general, presence of other competing functional groups produced catemer motifs whereas unsubstituted acids showed dimer. In this manuscript, we have synthesized a new aryl ether amine-based Schiff base with carboxylic acid functionality ( 1 ) and demonstrated polymorphic structure via catemer (1a) and dimer (1b) motifs in the solid state. In both the structure, carboxylic acid group adopted different orientation in the crystal lattice. The different $\mathrm{H}$-bonding lead to modulation of optical properties that was further supported highest occupied molecular orbital (HOMO) and lowest unoccupied molecular orbital (LUMO) calculation. Further the stability calculation indicates that catemer structure was more stable by $8.54 \mathrm{kcal} / \mathrm{mole}$ relative to dimer motifs. In contrast, naphthyl group attached carboxylic acid structure did not show neither dimer nor catemer motifs in the crystal lattice as compared to diethylaminophenyl group, which confirm the presence of other substituent or competing functional groups strongly influence on the motifs of supramolecular interactions.

\section{Introduction}

Molecular conformation and stacking arrangement of organic functional molecules play important role on their electrical, optical and optoelectronic properties in the solid state [1]. Supramolecular interactions such as $\mathrm{H}$-bonding, $\mathrm{p}$... p, $\mathrm{C}-\mathrm{H}$... $\mathrm{p}$ and dipole interactions strongly influenced on the molecular organization and conformation in the solid state [2]. Particularly, polymorphism, a chemical molecule exist in more than one form in the crystalline state, is an interesting phenomenon since it provides a pathway to understand the role of molecular conformation, organization and the resulting solid state properties of organic functional molecules [3]. For instance, p-conjugated planar pentacene exhibited four different polymorphs and molecular conformation and packing dependent charge carrier mobility [4]. Organic semiconductors such as dithiophene-tetrathiafulvalene and 1,3-diazapentacene are also known to exhibit polymorph dependent electrical properties [5]. Polymorphism provides a simple strategy to switch and tune the fluorescence of organic molecules in the solid state without doing tiresome iterative synthesis $[6,7]$. Polymorphism induced fluorescence tuning has been reported with organic functional molecules in the solid state $[7,8]$. Interestingly, 2,2':6,2"-terpyridine showed rare reversible on-off fluorescence switching via reversible structural change with controlled heating [9]. 9-anthryl-pyrazole showed reversible fluorescence switching between blue and greenish blue due to reversible change of intermolecular interactions and molecular packing in the solid state [10]. Hence, exploring and manipulating organic functional molecules that contain $\mathrm{H}$-bonding functionality such as $\mathrm{COOH}, \mathrm{CONH}, \mathrm{NH}_{2}, \mathrm{SO}_{3} \mathrm{H}$ for developing designed structural motifs for realizing new or enhanced materials properties received significant attention [2]. In this regard, carboxylic acid supramolecular synthon has been extensively employed for constructing supramolecular network solids using organic as well as metal organic frameworks [11]. Carboxylic acid exhibits either dimer or catemer $\mathrm{H}$-bonding motifs depending on the molecular structure and other functional groups present in the molecule [12]. Both mono and dicarboxylic 
acids showed dimer motifs when there are no other H-bonding groups present in the structure. However, catemer motifs dominates when other $\mathrm{H}$-bonding functional groups competes with each other. Aryl ether amine-based Schiff base molecules are of interesting research topic as it possess supramolecular interactions where the optoelectronic properties could be exploited from sensing to structure dependent mechanofluorochromism (MFC) $[13,14]$. In this manuscript, synthesis and polymorphic structure via catemer and dimer motif of a diethylamine substituted aryl-ether amine Schiff base with carboxylic acid as well as hydroxyl functionality (1) have been investigated in solid state. Interestingly, crystallization of 1 produced two different colored crystals, brown (1a) and clear yellow crystals (1b). Structural analysis revealed that carboxylic acid in 1a showed catemer motif whereas $\mathbf{1 b}$ displayed dimer network in the solid state. Further, comparison of molecular conformation showed different orientation of carboxylic acid in both the structure. To gain the role of carboxylic motif change in the color of 1 , computational studies were performed that clearly showed lower band for $\mathbf{1 a}(3.62 \mathrm{eV})$ compared to $\mathbf{1 b}(3.74 \mathrm{eV})$. The stability calculation indicated higher stability for $\mathbf{1 a}$ compared to $\mathbf{1 b}$. Thus, the present studies further substantiate the role of supramolecular network on the optical properties and dominance of catemer motifs in the carboxylic acid synthon when other functionality and substituent present in the structure.

\section{Experimental Section}

2-Fluoro-nitrobenzene, 2-cyanophenol, $\mathrm{NaBH}_{4}, \mathrm{Pd} / \mathrm{C}$, 2-hydroxy naphthaldehyde and 2-hydroxy-4diethylamino benzaldehyde were obtained from sigma/Aldrich and used as received. All chemicals are used as received. The aryl-ether amine precursors were synthesized by following our recently reported procedure [13].

Synthesis of 1

An ethanolic solution ( $30 \mathrm{ml}$ ) of 2-hydroxy-4-diethylamino benzaldehyde $(220 \mathrm{mg}, 1.1 \mathrm{mmol})$ was added drop-wise into 2-(2'-aminophenoxy)benzene carboxylic acid $(230 \mathrm{mg}, 1 \mathrm{mmol})$ dissolved in ethanol (10 $\mathrm{ml}$ ) under stirring at room temperature. After the addition, the reaction mixture was refluxed for $10 \mathrm{~h}$. The cooling of reaction mixture produced precipitate that was filtered and washed with ethanol and dried under vacuum.

1: Yield $=80 \% .{ }^{1} \mathrm{H} \mathrm{NMR}\left(300 \mathrm{MHz}, \mathrm{CDCl}_{3}\right) \mathrm{d} 13.35(\mathrm{~s}, 1 \mathrm{H}(\mathrm{COOH})), 8.36(\mathrm{~s}, 1 \mathrm{H}$ (imine)), $1 \mathrm{H}), 8.13(\mathrm{dd}, J=$ $7.8 \mathrm{~Hz}, 1 \mathrm{H}), 7.60(\mathrm{~s}, 1 \mathrm{H}(\mathrm{OH})), 7.30-7.20(\mathrm{~m}, 2 \mathrm{H}), 7.16-7.10(\mathrm{~m}, 2 \mathrm{H}), 7.07-7.01(\mathrm{~m}, 3 \mathrm{H}), 6.69-6.67(\mathrm{~m}, 1 \mathrm{H})$, $6.14(\mathrm{dd}, J=8.7 \mathrm{~Hz}, 1 \mathrm{H}), 5.99(\mathrm{~d}, J=2.4 \mathrm{~Hz}, 1 \mathrm{H}), 5.72(\mathrm{~s}, 1 \mathrm{H}), 3.29(\mathrm{q}, J=6.9,7.2 \mathrm{~Hz}, 4 \mathrm{H}), 1.10(\mathrm{t}, J=7.0$ $\mathrm{Hz}, 6 \mathrm{H}) .{ }^{13} \mathrm{C}$ NMR $\left(75 \mathrm{MHz}, \mathrm{CDCl}_{3}\right)$ d 191.9, 167.2, 166.2, 164.4, 159.3, 156.1, 153.3, 146.9, 138.3, 135.4, 135.0, 133.5, 132.9, 126.4, 125.9, 123.4, 121.7, 121.1, 119.8, 116.9, 116.2, 108.7, 104.6, 104.4, 97.9, 44.8, 12.7. $\mathrm{C}_{24} \mathrm{H}_{24} \mathrm{~N}_{2} \mathrm{O}_{2}$ (404.46): calcd. C 71.27, H 5.98, N 6.93; found C 71.56, H 5.83, N 7.07.

\section{Characterization}


NMR spectra were measured on a Bruker $300 \mathrm{MHz}$ AVANCE-II. Absorption spectra were recorded using Perking Elmer Lambda 1050. Single crystals of 1 was coated with paratone-N oil and diffraction data

was measured at $100 \mathrm{~K}$ with synchrotron radiation $(\lambda=0.62998 \AA)$ on an ADSC Quantum-210 detector at 2D SMC with a silicon (111) double crystal monochromator (DCM) at the Pohang Accelerator Laboratory, Korea. CCDC Nos. - 1823901 (1a) and 1823902 (1b) contain the supplementary crystallographic data for this paper. The HOMO, LUMO and band gap of $\mathbf{1 a}$ and $\mathbf{1 b}$ are studied using B3PW91/6-31+G(d,p) level theory (Gaussian 09 package).

\section{Results And Discussion}

Amine precursors and the corresponding Schiff base molecule (1) was synthesized by following procedure reported in the literature [13, Scheme 1a]. The reaction between 2-cyanophenol and 2-fluoronitrobenzene in presence of $\mathrm{K}_{2} \mathrm{CO}_{3}$ in DMSO at $110{ }^{\circ} \mathrm{C}$ resulted in the formation of 2-(2nitrophenoxy)benzonitrile. The nitro group was reduced followed by oxidation of $\mathrm{CN}$ to $\mathrm{COOH}$ produced amine precursor. Schiff base 1 was synthesized via a simple condensation reaction between amine and 2-hydroxy 4-diethylamino benzaldehyde in ethanol. In contrast to other carboxylic acid functionalzied aryl-ether amine Schiff base [13], 1 did not show solid state fluorescnce as well as coloro/fluorometric sensing of metal ions that could be attributed to the isomerism of imine $(\mathrm{C}=\mathrm{N})$ and photoelectron transfer effect (PET) of diethylamino group. As prepared solid of 1 appeared as brown color. The carboxylic acid supramoelcular synthon is known to exhibit either dimer or catemer motifs in the solid state depend on the other functional molecules present in the structure [Scheme 1b]. Hence crystal structue of 1 could be interesting to study since it contain other $\mathrm{H}$-bonding hyroxyl and imine hydrogen functional group along with diethyl amine substitutent. Single crystals of 1 were grown from ethyl acetate by slow evaporation. Interestingly, 1 produed concomittant polymorhs with completely different colored crystals, brown (1a) and clear yellow (1b) colored crystals. $\mathbf{1 a}$ and $\mathbf{1} \mathbf{b}$ crystals were separated manually. It is noted that higher quantity of $\mathbf{1 a}$ crystals was formed compared to $\mathbf{1 b}$.

Structural analysis of $\mathbf{1} \mathbf{a}$ and $\mathbf{1} \mathbf{b}$ revelaed different molecular conformation and carboxylic acid orientation in the crystal lattice [Figure 1a, Table 1]. The hydroxyl group and carboxylic group are oriented in opposite orientation in $\mathbf{1 a}$ whereas both groups oriented in the same direction in $\mathbf{1 b}$. In both the structure, hydroxyl group formed strong intramolecular $\mathrm{H}$-bonding with imine nitrogen atom. It is noted that the carboxylic acid hydrogen atom of $\mathbf{1 b}$ is disordered with $50 \%$ intramolecule and $50 \%$ inter molecule [Figure S1]. The disordered 50\% intermolecular hydrogen of carboxlic acid in 1a produced open catemer $\mathrm{H}$-bonding motifs by hydrogen bonding with carbonyl oxygen of another moelcule that lead to helical network structure along $b$-axis in the crystal lattice [Figure 1b,c, Table 2]. The open catemer chain hydrogen bond motif arise in 21 screw crystallographic symmetric site. The open catemer $\mathrm{H}$-bonding in the crystal lattice of $\mathbf{1 a}$ further supported by $\mathrm{C}-\mathrm{H} . . . \mathrm{p}$ interactions. The $\mathrm{C}-\mathrm{H} . . . \mathrm{O}$ intermolecular interactions between hydroxyl oxygen and diethyl hydrogen and $\mathrm{C}-\mathrm{H}$...p interactions lead to the formation of interconected square network structure in the crystal lattice [Figure 1d]. The packing of 1a showed opposite arrangment molecules in the crystal lattice [Figure 1e]. In contrast, carboxylic acid in 1 $\mathbf{b}$ showed 
R22(8) dimer motifs in the crystal lattice [Figure 2a, Table 3]. The closed dimer motif lay on inversion symmetry site. The disordered $50 \%$ intermolecular hydrogen produced dimer network and disordered $50 \%$ intramolecular hydrogen exhibited intramolecular hydrogen bond with oxygen. The weak C-H...O and C$\mathrm{H}$.... intermoelcular interactions interconnects the dimer along the $a$ and $b$-axis in the crystal lattice [Figure $2 b, c]$. The moelcular packing showed opposite arrangment of molecules in the crystal lattice [Figure 2d]. Thus, carboxylic acid of 1 exhibited both catemer and dimer motifs in the solid state. In contrast, the previuosly reported molecule where diethylamine substituted phenyl was replaced by naphthalene, carboxylic acid in the crystal lattice did not show neither dimer or catemer motifs [13, Figure 3]. The carboxylic acid hydroxyl group formed $\mathrm{O}-\mathrm{H} . . . \mathrm{O}$ intermoelcular $\mathrm{H}$-bonding with phenolic hydroxyl group of another molecule that formed intramoelcular $\mathrm{H}$-bonding with imine nitrgen atom. Surprisingly the carbonyl oxygen of carboxylic acid showed $\mathrm{C}-\mathrm{H} . . . \mathrm{O} \mathrm{H}$-bonding with phenyl hydrogen of another moelcule [Figure. 3]. Further, strong p...p interactions between naphthalene and aryl-ether amine phenyl groups interconnected the moelcules in the crystal lattice. It did not show polymorphism that might due to the presence of strong p...p interactions. The comparison crystal structure indicates that although carboxlic acid could form strong intermoelcular H-bonding in the solid state, the presence of other substituent or competing fucntional groups strongly influence on the motifs of supramoelcular interactions. Differential scanning caolorimetry (DSC) of $\mathbf{1 a}$ and $\mathbf{1 b}$ (Figure S2) reveals different carobxylic motifs in the polymorphs lead to different melting point, $1 \mathrm{a}$ melts at $165^{\circ} \mathrm{C}$ and $\mathbf{1 b}$ melts at $197^{\circ} \mathrm{C}$ where as IR spectra of $\mathbf{1 a}$ and $\mathbf{1 b}$ showed similar peak profile with small peak differences between the polymorphs (Figure S3 and Table S1).

Computational studies were performed for polymorphic structures of 1 to gain the insight on the predominance of $\mathbf{1 a}$ over $\mathbf{1 b}$ as well as color change. The isodensity surface plot (isodensity contour $=$ 0.02) of the HOMOs of $\mathbf{1 a}$ indicated that electron density was predominantly localized on diethylamino phenyl as well as imino phenyl groups [Figure 4]. The electron density in the LUMOs was mostly localized on the imine nitrogen acceptor. Similarly, electron density in the HOMOs of $\mathbf{1 b}$ was mainly occupied in the diethylamino phenyl as well as imino phenyl groups and LUMOs showed localizng electron density on the imine groups. However, LUMOs of $\mathbf{1 b}$ revealed that electron density also slightly occupied on the carboxylic acid phenyl groups. 1a showed lower optical band gap of $3.62 \mathrm{eV}$ compared to $\mathbf{1 b}$ that showed optical band gap of $3.74 \mathrm{eV}$ and supported the color change in the solid state. Carboxylic acid supramolecular synthon is known to exhibit catemer motifs when other competing functional groups or substituent present in the structure [12]. Hence the stability of the $\mathbf{1 a}$ and $\mathbf{1} \mathbf{b}$ polymorphs was calculated for finding more stable polymorphs. The stability calculations indicate that polymorph $1 \mathrm{a}$ is 8.54 $\mathrm{kcal} /$ mole more stable than polymorph $\mathbf{1 b}$. Further to ascertain the stability of intermolecular interactions in the crystal lattice, the dimer of $\mathbf{1 a}$ and $\mathbf{1 b}$ were taken from the crystal structure and shown in Figure S4. The stabilization energy of the dimer $\mathbf{1} \mathbf{a}$ and $\mathbf{1} \mathbf{b}$ were calculated at DFT/M06-2X/DIDZ level of theory [15]. The binding energy of the dimer $1 \mathrm{a}$ and $1 \mathrm{~b}$ are $-8.10 \mathrm{kcal} / \mathrm{mol}$ and $-10.05 \mathrm{kcal} / \mathrm{mol}$, respectively. Polymorph $\mathbf{1 b}$ is relatively more stable than $1 \mathrm{a}$ and support the melting point observed from DSC. The crystal structure clearly shows that it has hydrogen bonding as well as non-covalent interactions $(\pi-\mathrm{H}$ interaction and $\pi-\pi$ interaction). The calculations reported in this article were performed using the 
GAUSSIAN-09 suite of programs [15a]. Thus the present studies also confirmed that substitutent or other competing functional group presence lead to the catemer motifs dominance in the carboxylic acid supramolecular interactions.

\section{Conclusion}

In conclusion, aryl-ether amine based new Schiff base molecule with carboxylic acid (1) functionality was synthesized that showed polymorphic structure via dimer and catemer motifs in the crystal lattice.

Crystallization of $\mathbf{1}$ from ethyl acetate produced concomitant polymorphs $\mathbf{1} \mathbf{a}$ and $\mathbf{1} \mathbf{b}$. The carboxylic acid in 1a polymorph showed catemer motifs whereas $\mathbf{1 b}$ showed dimer network structure. The differences in the carboxylic acid supramolecular interactions, molecular conformation and packing lead to different colored solids, brown for $\mathbf{1 a}$ and clear yellow for $\mathbf{1 b}$. HOMO-LUMOs calculation suggested lower band gap for $\mathbf{1 a}$ compared to $\mathbf{1 b}$ and supported the color change. Further, $1 \mathrm{a}$ was $8.54 \mathrm{kcal} / \mathrm{mole}$ more stable than $\mathbf{1 b}$ that further supported the role of competing functional group for inducing catemer dominance in the solid state. Interestingly, when diethyl amine phenyl group was replaced by naphthalene unit, carboxylic acid did not show catemer as well as dimer motifs rather hydroxyl proton formed intermolecular interaction with phenolic hydroxyl oxygen of another molecule. Thus, the carboxylic acid of aryl-ether amine molecule showed different supramolecular interactions depends on the substituent and functional group in the structure and modulate the optical properties.

\section{Declarations}

\section{Acknowledgement}

The authors are thankful to the deanship of scientific research at King Khalid University

\section{Funding}

This work was funded by King Khalid University through research group project under grant number R.G.P.1/ 35/42

\section{Conflicts of interest}

The authors declare that they have no known competing financial interests or personal relationships that could have appeared to influence the work reported in this paper.

\section{Availability of data and material}

CCDC Nos. - 1823901 (1a) and 1823902 (1b) contain the supplementary crystallographic data for this paper.

\section{Code availability}


Not Applicable

\section{Authors' contributions}

Mehboobali Pannipara: Writing - original draft and Methodology. Abdullah G. Al-Sehemi: Conceptualization and supervision.

\section{References}

[1] (a) B. Fraboni, A. Fraleoni-Morgera, Y. Geerts, A. Morpurgo, V. Podzorov, Adv. Funct. Mater. 26 (2016) 2229;

(d) D. Gonzalez-Rodriguez, A. P. H. Schenning, Chem. Mater. 23 (2011) 310;

(f) M. Klaus, V. Vasylyeva, CrystEngComm. 12 (2010) 3989;

(g) S. P. Anthony, S. Varughese, S. M. Draper, J. Phys. Org. Chem. 23 (2010) 1074.

[2] (a) G. R. Desiraju, Crystal Engineering. The Design of Organic Solids; Elsevier: Amsterdam, 1989;

(d) B. Moulton, M. J. Zaworotko, From Molecules to Crystal Engineering: Supramolecular Isomerism and Polymorphism in Network Solids, Chem. Rev. 101 (2001) 1629.

(c) X. Gu, J. Yao, G. Zhang, Y. Yan, C. Zhang, Q. Peng, Q. Liao, Y. Wu, Z. Xu, Y. Zhao, H. Fu, D. Zhang, Polymorphism-Dependent Emission for Di(p-methoxylphenyl)dibenzofulvene and Analogues: Optical Waveguide/Amplified Spontaneous Emission Behaviors, Adv. Funct. Mater. 23 (2012) 4862;

(d) R. Wei, P. Song, A. Tong, Reversible Thermochromism of Aggregation-Induced Emission-Active Benzophenone Azine Based on Polymorph-Dependent Excited-State Intramolecular Proton Transfer Fluorescence, J. Phys. Chem. C 117 (2013) 3467.

[4] Q. Tang, D. Zhang, S. Wang, N. Ke, J. Xu, J. C. Yu, Q. Miao, A Meaningful Analogue of Pentacene: Charge Transport, Polymorphs, and Electronic Structures of Dihydrodiazapentacene Chem. Mater. 21 (2009) 1400.

[5] (a) R. Pfattner, M. M. Torrent, I. Bilotti, A. Brillante, S. Milita, F. Liscio, F. Biscarini, T. Marszalek, J. Ulanski, A. Nosal, M. G. Lipman, M. Leufgen, G. Schmidt, L. W. Molenkamp, V. Laukhin, J. Veciana, C. Rovira, High-Performance Single Crystal Organic Field-Effect Transistors Based on Two DithiopheneTetrathiafulvalene (DT-TTF) Polymorphs, Adv. Mater. 22 (2010) 4198;

[6] (a) S. P. Anthony, Organic Solid-State Fluorescence: Strategies for Generating Switchable and Tunable Fluorescent Materials, ChemPlusChem. 7 (2012) 518;

(b) D. Frath, J. Massue, G. Ulrich, R. Ziessel, Luminescent materials: locking $\pi$-conjugated and heterocyclic ligands with boron(III), Angew. Chem. Int. Ed. 53 (2014) 2290; 
(b) Y. Zhao, H. Gao, Y. Fan, T. Zhou, Z. Su, Y. Liu, Y. Wang, Thermally Induced Reversible Phase Transformations Accompanied by Emission Switching Between Different Colors of Two Aromatic-Amine Compounds, Adv. Mater. 21 (2009) 3165.

[8] (a) C. Kitamura, T. Ohara, N. Kawatsuki, A. Yoneda, T. Kobayashi, H. Naito, T. Komatsu, T. Kitamura, Conformational polymorphism and optical properties in the solid state of 1,4,7,10-tetra(n-butyl)tetracene, CrystEngComm. 9 (2007) 644;

(b) Z. Zhang, Y. Zhang, D. Yao, H. Bi, I. Javed, Y. Fan, H. Zhang, Y. Wang, Anthracene-ArrangementDependent Emissions of Crystals of 9-Anthrylpyrazole Derivatives, Cryst. Growth Des. 9 (2009) 5069;

(e) S. P. Anthony, Polymorph-Dependent Solid-State Fluorescence and Selective Metal-lon-Sensor Properties of 2-(2-Hydroxyphenyl)-4(3H)-quinazolinone, Chem. Asian J. 7 (2012) 374.

[9] T. Mutai, H. Satou, K. Araki, Reproducible on-off switching of solid-state luminescence by controlling molecular packing through heat-mode interconversion, Nat. Mater. 4 (2005) 685.

[10] H. Y. Zhang, Z. L. Zhang, K. Q. Ye, J. Y. Zhang, Y. Wang, Organic Crystals with Tunable Emission Colors Based on a Single Organic Molecule and Different Molecular Packing Structures, Adv. Mater. 18 (2006) 2369.

[11] (a) G. R. Desiraju, Crystal Engineering: From Molecule to Crystal, J. Am. Chem. Soc., 135 (2013) 9952;

[12] (a) T. Beyer, Sarah L. Price, Dimer or Catemer? Low-Energy Crystal Packings for Small Carboxylic Acids, J. Phys. Chem. B 104 (2000) 2647.

(c) A. M. Moragues-Bartolome, W. Jonesa, A. J. Cruz-Cabeza, Synthon preferences in cocrystals of ciscarboxamides:carboxylic acids, CrystEngComm, 14 (2012) 2552.

[13] (a) A. Kundu, P. S. Hariharan, K. Prabakaran, S. P. Anthony, Developing new Schiff base molecules for selective colorimetric sensing of $\mathrm{Fe}^{3+}$ and $\mathrm{Cu}^{2+}$ metal ions: Substituent dependent selectivity and colour change, Sens. Actuators B 206 (2015) 524;

[15] (a) T. Vreven, K. N. Kudin, J. C. Burant, J. M. Millam, S. S. Iyengar, J. Tomasi, V. Barone, B. Mennucci, M. Cossi, G. Scalmani, N. Rega, G. A. Petersson, H. Nakatsuji, M. Hada, M. Ehara, K. Toyota, R. Fukuda, J. Hasegawa, M. Ishida, T. Nakajima, Y. Honda, O. Kitao, H. Nakai, M. Klene, X. Li, J. E. Knox, H. P. Hratchian, J. B. Cross, V. Bakken, C. Adamo, J. Jaramillo, R. Gomperts, R. E. Stratmann, O. Yazyev, A. J. Austin, R. Cammi, C. Pomelli, J. W. Ochterski, P. Y. Ayala, K. Morokuma, G. A. Voth, P. Salvador, J. J. Dannenberg, V. G. Zakrzewski, S. Dapprich, A. D. Daniels, M. C. Strain, O. Farkas, D. K. Malick, A. D. Rabuck, K. Raghavachari, J. B. Foresman, J. V. Ortiz, Q. Cui, A. G. Baboul, S. Clifford, J. Cioslowski, B. B. Stefanov, G. Liu, A. Liashenko, P. Piskorz, I. Komaromi, R. L. Martin, D. J. Fox, T. Keith, M. A. Al-Laham, C. Y. Peng, A. Nanayakkara, M. Challacombe, P. M. W. Gill, B. Johnson, W. Chen, M. W. Wong, C. Gonzalez, J. A. Pople, Gaussian 09, Revision C.02; Gaussian, Inc., Wallingford CT 2004. 
(b) S. Kim, S. Karthikeyan, N. J. Singh, How Different Are Aromatic $\pi$ Interactions from Aliphatic $\pi$ Interactions and Non- $\pi$ Stacking Interactions? J. Chem. Theor. Comput., 7 (2011) 3471.

\section{Tables}

Table 1. Crystallographic detail of $\mathbf{1 a}$ and $\mathbf{1} \mathbf{b}$. 


\begin{tabular}{|c|c|c|}
\hline Compound & $1 \mathbf{a}(1823901)$ & 1b (1823902) \\
\hline chemical formula & $\mathrm{C}_{24} \mathrm{H}_{24} \mathrm{~N}_{2} \mathrm{O}_{4}$ & $\mathrm{C}_{24} \mathrm{H}_{24} \mathrm{~N}_{2} \mathrm{O}_{4}$ \\
\hline formula mass & 404.45 & 404.45 \\
\hline crystal system & Monoclinic & Triclinic \\
\hline space group & $P 2_{1} / n$ & $P$ \\
\hline$a(\AA)$ & $15.793(3)$ & $7.5900(15)$ \\
\hline$b(\AA)$ & $7.4890(15)$ & $9.5790(19)$ \\
\hline$c(\AA)$ & $17.893(4)$ & $13.821(3)$ \\
\hline$\beta($ deg $)$ & $100.44(3)$ & $95.49(3)$ \\
\hline unit cell volume $\left(\AA^{3}\right)$ & 2081.3(8) & $989.2(4)$ \\
\hline temp $(\mathrm{K})$ & 100 & 100 \\
\hline Z & 4 & 2 \\
\hline Wavelength $(\AA)$ & 0.610 & 0.610 \\
\hline Absorption coefficient & $0.065 \mathrm{~mm}-1$ & $0.068 \mathrm{~mm}-1$ \\
\hline$F(000)$ & 856 & 428 \\
\hline Theta range for data collection & 2.537 to $25.000^{\circ}$ & 1.845 to $24.998^{\circ}$. \\
\hline Reflections collected & 20622 & 10635 \\
\hline Independent reflections & $5484[\mathrm{R}($ int $)=0.0293]$ & $5351[\mathrm{R}(\mathrm{int})=0.0093]$ \\
\hline Completeness to theta $=21.469^{\circ}$ & $96.0 \%$ & $97.3 \%$ \\
\hline Max. and min. transmission & 0.994 and 0.990 & 0.983 and 0.979 \\
\hline Refinement method & Full-matrix least-squares on F2 & Full-matrix least-squares on F2 \\
\hline Data / restraints / parameters & 5484 / 2 / 280 & $5351 / 0 / 275$ \\
\hline Goodness-of-fit on F2 & 1.067 & 1.035 \\
\hline Final $R$ indices $[\mid>2 \operatorname{sigma}(I)]$ & $R_{1}=0.0493, w R_{2}=0.1421$ & $\mathrm{R}_{1}=0.0417, \mathrm{wR}_{2}=0.1165$ \\
\hline $\mathrm{R}$ indices (all data) & $\mathrm{R}_{1}=0.0603, w \mathrm{R}_{2}=0.1494$ & $\mathrm{R}_{1}=0.0435, \mathrm{wR}_{2}=0.1180$ \\
\hline
\end{tabular}


Table 2. Hydrogen bonds for $1 \mathbf{a}\left[\AA\right.$ and $\left.^{\circ}\right]$.

\begin{tabular}{|lllll|}
\hline $\mathrm{D}-\mathrm{H} \ldots \mathrm{.} A$ & $\mathrm{~d}(\mathrm{D}-\mathrm{H})$ & $\mathrm{d}(\mathrm{H} \ldots \mathrm{A})$ & $\mathrm{d}(\mathrm{D} \ldots \mathrm{A})$ & $<(\mathrm{DHA})$ \\
\hline $\mathrm{O}(2)-\mathrm{H}\left(102^{\wedge} \mathrm{a}\right) \ldots \mathrm{O}(1) \# 1$ & $0.944(19)$ & $1.94(2)$ & $2.8784(16)$ & $171(4)$ \\
\hline $\mathrm{O}(2)-\mathrm{H}\left(2 \mathrm{O} 2^{\wedge} \mathrm{b}\right) \ldots \mathrm{O}(3)$ & $0.940(19)$ & $1.96(4)$ & $2.6676(16)$ & $130(4)$ \\
\hline $\mathrm{O}(4)-\mathrm{H}(4) \ldots \mathrm{N}(1)$ & 0.84 & 1.87 & $2.6141(16)$ & 147.2 \\
\hline
\end{tabular}

Symmetry transformations used to generate equivalent atoms:

$\# 1-x+3 / 2, y+1 / 2,-z+1 / 2$

Table 3. Hydrogen bonds for $\mathbf{1 b}\left[\AA \AA\right.$ and $\left.{ }^{\circ}\right]$.

\begin{tabular}{|lllll|}
\hline $\mathrm{D}-\mathrm{H} \ldots \mathrm{.} A$ & $\mathrm{~d}(\mathrm{D}-\mathrm{H})$ & $\mathrm{d}(\mathrm{H} \ldots \mathrm{A})$ & $\mathrm{d}(\mathrm{D} \ldots \mathrm{A})$ & $<(\mathrm{DHA})$ \\
\hline $\mathrm{O}(2)-\mathrm{H}\left(102^{\wedge} \mathrm{a}\right) \ldots \mathrm{O}(1) \# 1$ & $0.916(18)$ & $1.78(2)$ & $2.6864(15)$ & $168(4)$ \\
\hline $\mathrm{O}(2)-\mathrm{H}\left(2 \mathrm{O} 2^{\wedge} \mathrm{b}\right) \ldots \mathrm{O}(3)$ & $0.927(18)$ & $2.05(4)$ & $2.6322(13)$ & $119(3)$ \\
\hline $\mathrm{O}(4)-\mathrm{H}(4) \ldots \mathrm{N}(1)$ & 0.84 & 1.88 & $2.6297(12)$ & 147.3 \\
\hline
\end{tabular}

Symmetry transformations used to generate equivalent atoms:

$\# 1-\mathrm{x},-\mathrm{y},-\mathrm{z}$

Figures 

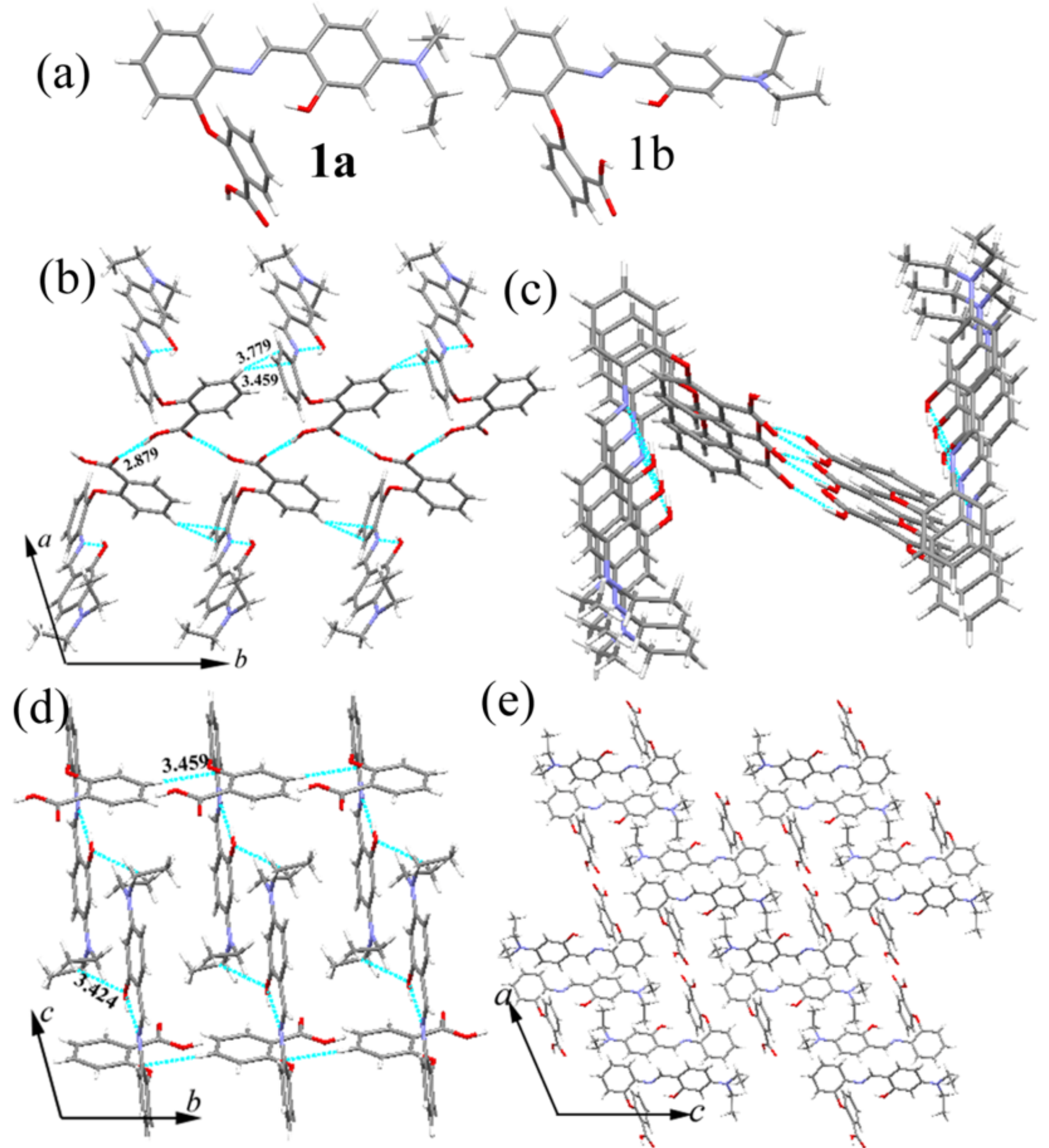

(e)

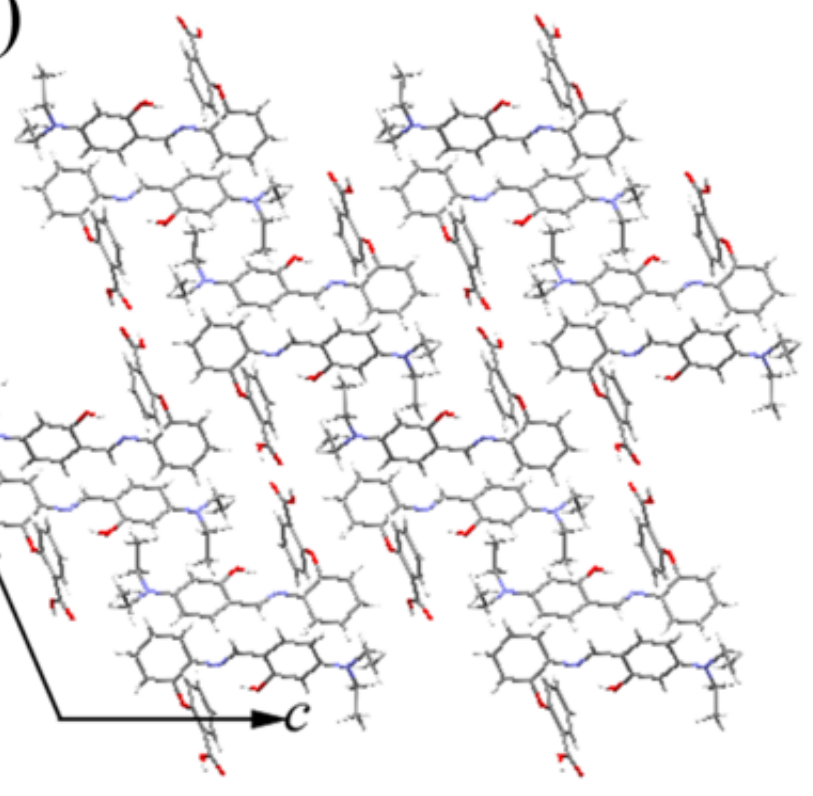

Figure 1

(a) Polymorphic structure of 1. (b) Catemer H-bonding, (c) helical assembly of carboxylic acid, (d) intermolecular $\mathrm{H}$-bonding induced square structure and (e) molecular packing in the crystal lattice of 1a. $\mathrm{C}$ (grey), $\mathrm{N}$ (blue), $\mathrm{O}$ (red), $\mathrm{H}$ (white). $\mathrm{H}$-bonding, $\mathrm{C}-\mathrm{H} . . . \mathrm{O}$ and $\mathrm{C}-\mathrm{H} . . . \pi$ interactions (broken line) distances are marked in $\AA$. 


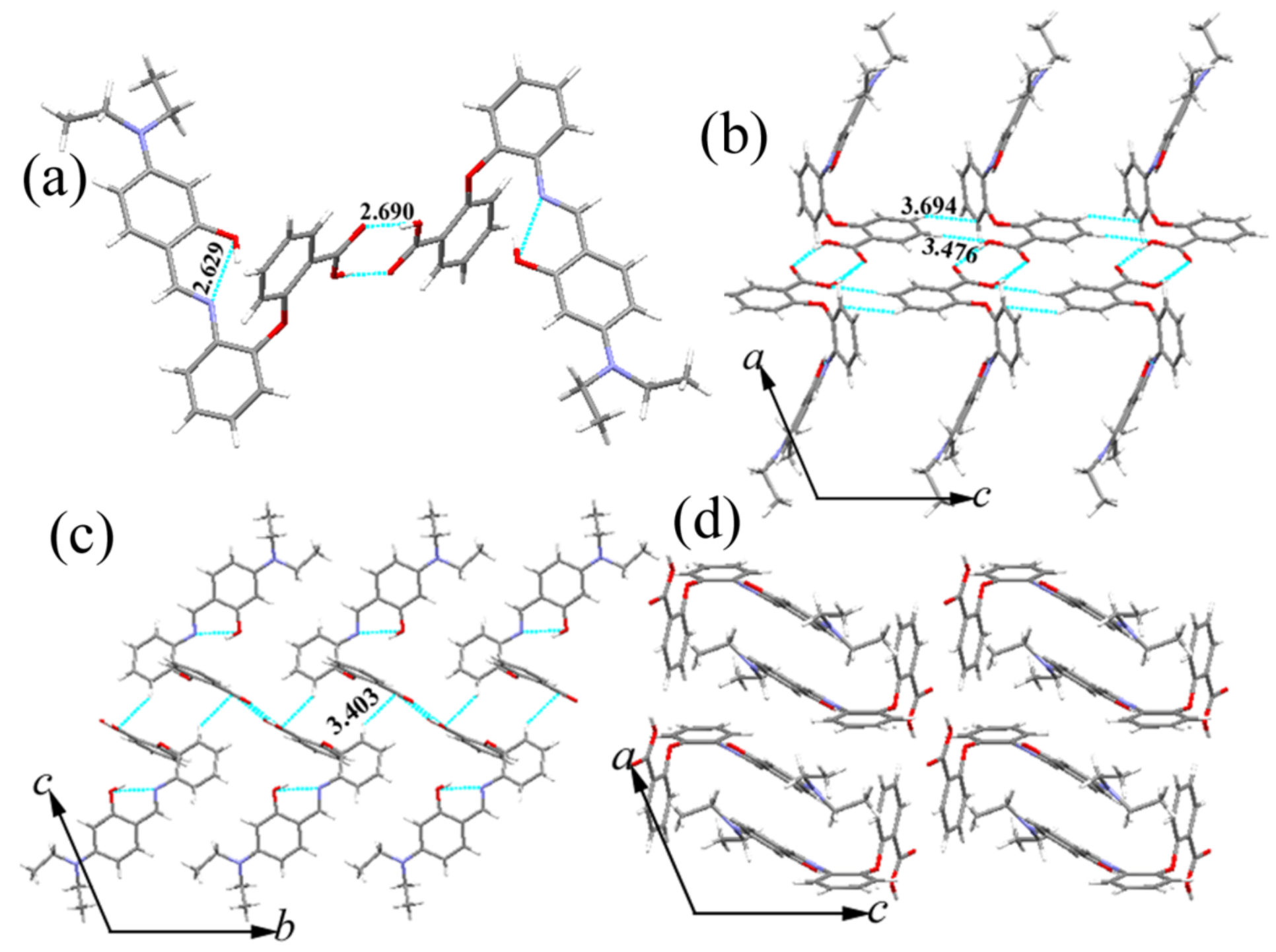

Figure 2

(a) Intramolecular H-bonding and dimer motifs, (b), (c) intermolecular interactions induced network structure and (d) opposite molecular packing in the crystal lattice of 1b. C (grey), N (blue), O (red), H (white). H-bonding, $\mathrm{C}-\mathrm{H} \ldots . . \mathrm{O}$ and $\mathrm{C}-\mathrm{H} . . . \pi$ interactions (broken line) distances are marked in $\AA$. 

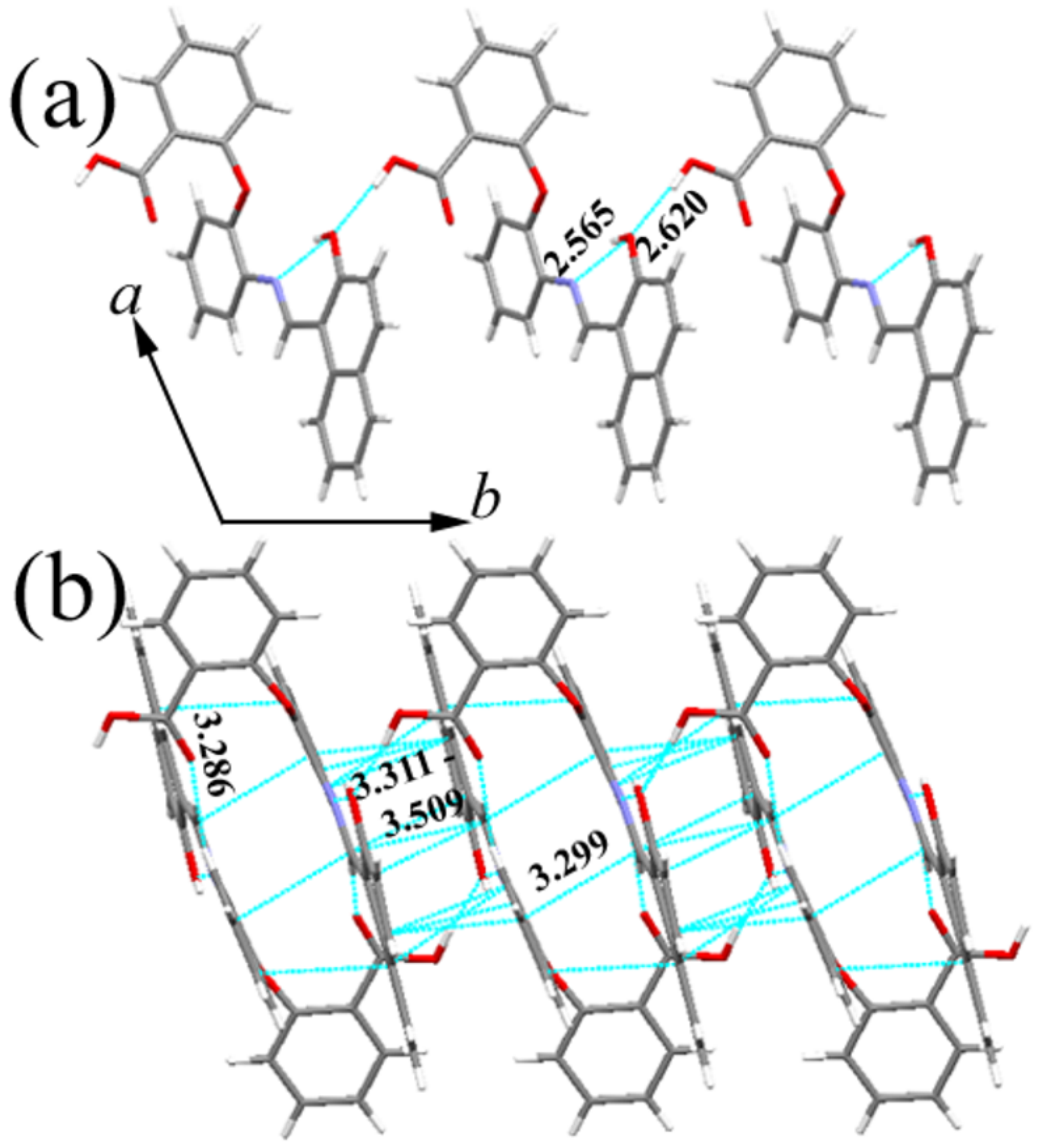

Figure 3

(a) Inter and Intramolecular H-bonding induced network structure and (b) C-Н... the crystal lattice. C (grey), N (blue), O (red), $\mathrm{H}$ (white). H-bonding, C-H...O and $\pi$... interactions (broken line) distances are marked in $\AA$. 

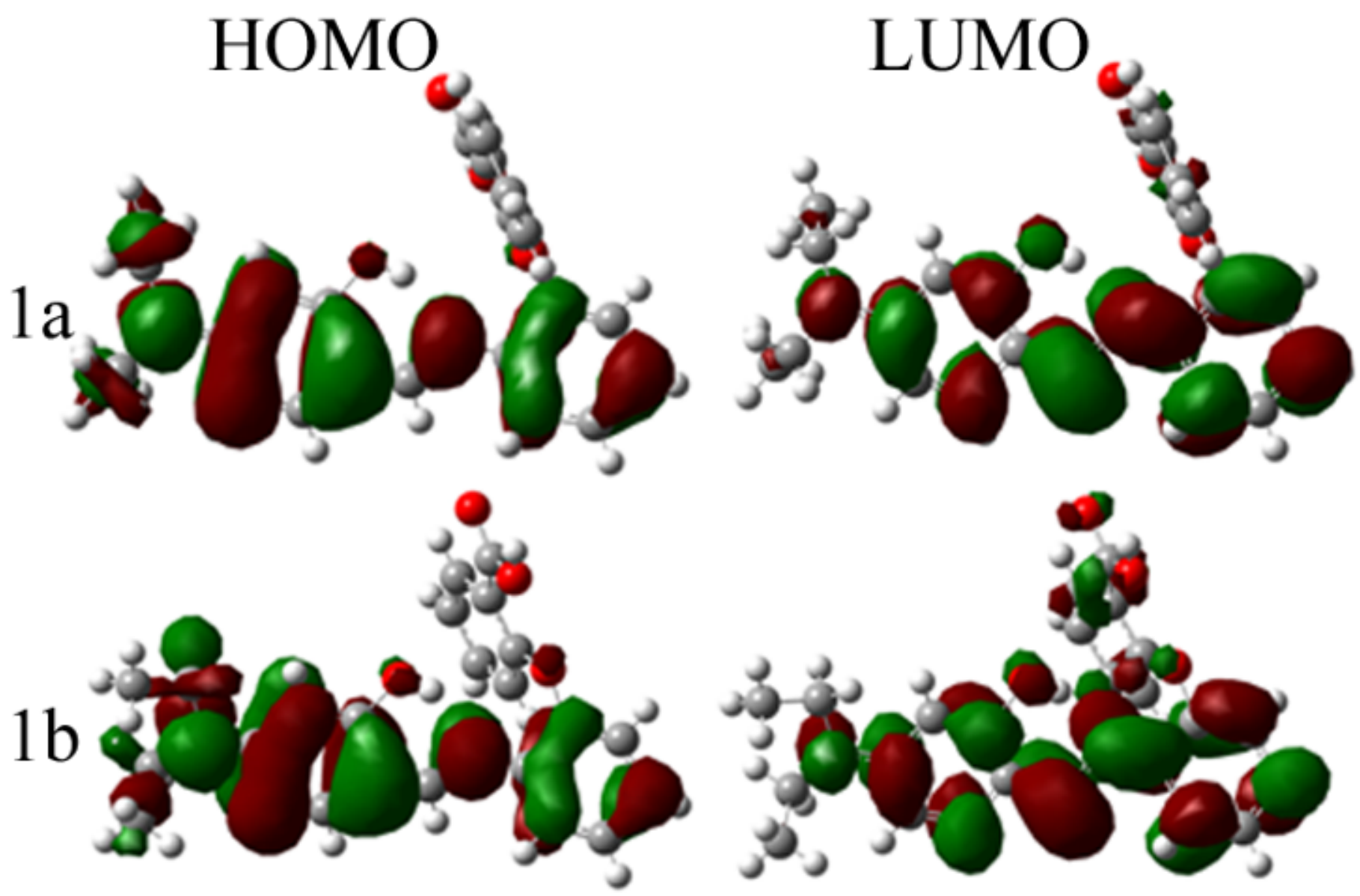

Figure 4

HOMO-LUMOs of 1.

\section{Supplementary Files}

This is a list of supplementary files associated with this preprint. Click to download.

- Scheme1.png

- SupportingInformation.docx

- 1823901.cif

- 1823902.cif 